\title{
THE ULTRASTRUCTURE OF MOUSE ARTICULAR CARTILAGE: COLLAGEN ORIENTATION AND IMPLICATIONS FOR TISSUE FUNCTIONALITY. A POLARISED LIGHT AND SCANNING ELECTRON MICROSCOPE STUDY AND REVIEW.
}

\author{
L. C. Hughes ${ }^{1}$, C. W. Archer ${ }^{2}$ and I. ap Gwynn ${ }^{1 *}$ \\ 1. The University of Wales Bioimaging laboratory, Institute of Biological Sciences, The University of Wales, \\ Aberystwyth, Wales, UK \\ 2. Connective Tissue Biology Laboratories, School of Biosciences, Cardiff University, Wales, UK
}

\begin{abstract}
.
Adult mouse articular cartilage (AC) has not been thoroughly described using high resolution imaging techniques, despite the fact that the availability of knockout mice with specific extracellular matrix (ECM) mutations have renewed interest in using the mouse as a model for a variety of different human conditions. With osteoarthritis affecting millions of people worldwide, investigations into the structure and, therefore, the ability of AC to act as a load-bearing tissue, are crucial for developing treatments and prevention techniques to limit the degree of severity in this condition. Cryofixation and formaldehyde fixation as well as chemical digestion of the uncalcified regions of AC were used in combination with bright field light, polarised light and scanning electron microscopy to image the structure of adult mouse AC. Chemical digestion of the tissue revealed unique insights into the structure of mouse $\mathrm{AC}$ and the high cellular density of the tissue. Tightly packed sheets of collagen fibrils formed the territorial matrix (TM) of the deep zone. These were observed closely surrounding the chondrons, after applying both chemical and cryofixation techniques. The interterritorial matrix (IM), in contrast, was more isotropically arranged. The results of the study have implications for the interpretation of biomechanical functionality of mouse $\mathrm{AC}$ with probable applications to other species.
\end{abstract}

Key Words: Articular cartilage, collagen matrix, ultrastructure, polarised light microscopy, scanning electron microscopy.

*Address for correspondence:

I. ap Gwynn

Institute of Biological Sciences

The University of Wales

Aberystwyth

Ceredigion

Wales SY23 3DA

Tel: $+44(0) 1970832551$

E-mail: iolo.apgwynn@gmx.com

\section{Introduction}

Articular cartilage (AC) is located on the surfaces of bones in all joints enabling smooth frictionless movement while also dissipating stresses in the joint and acting as a load-bearing surface. Hunter (1743) is one of the first to describe the structure of $\mathrm{AC}$ as velvet-like, consisting of parallel fibres, orientated perpendicularly to the bone, which bend under pressure but completely recover once the load has been removed. Since then, the study and understanding of $\mathrm{AC}$ has undergone large transformations. Today, research on AC is even more important due to the rising numbers of people suffering from diseases such as osteoarthritis and rheumatoid arthritis, debilitating conditions caused by a breakdown in the structure and functionality of $\mathrm{AC}$.

$\mathrm{AC}$ is comprised of chondrocytes surrounded by a dense extracellular matrix (ECM) providing the tissue with its unique biomechanical properties. Collagen forms the structural skeleton of the tissue, enclosing a hydrated proteoglycan (PG) gel that exerts an internal pressure of approximately 2-3atm (Urban et al., 1979; Basser et al., 1998). The collagen skeleton resists both the pressure from the PGs and the shear stresses produced during joint movement (Basser et al., 1998; Bank et al., 2000). The swelling pressures from the hydrated PGs partially resist load-bearing compressive forces and enable the rapid recovery of the AC. There are several different types of collagen and proteoglycan molecules within the tissue. The proteoglycans can be classified into the small leucine-rich proteoglycans (SLRPs), including decorin, fibromodulin, biglycan, lumican, epiphycan and keratan (Iozzo and Murdoch, 1996) and much larger macromolecules that form aggregates with hyaluronic acid, the largest of which is called aggrecan (Hascall and Hascall, 1981; Hagg et al., 1997). The collagens are also very diverse. Collagens identified in AC include the cartilage specific collagen types II, IX, X and XI as well as the more universally distributed types III, V, VI, XII and XIV (Eyre et al., 1987; Burgesson and Nimni, 1991; Thomas et al., 1994; Wotton and Duance, 1994). Collagens type II, III, $\mathrm{V}$ and XI are all classical fibril forming collagens whilst most of the other collagens in AC are fibril associated collagens with interrupted helices (FACIT), which associate with the fibril forming types (Thomas et al., 1994; Olsen and Ninomiya, 1999a, 1999b). The exceptions to these groups are collagen type $\mathrm{X}$, a short chain collagen, and collagen type VI, which has not yet been classified (Olsen and Ninomiya, 1999c). 
While the molecular components of the tissue have been well characterised and many of the collagen-collagen and collagen-proteoglycan interactions described under in vivo and in vitro conditions (Hendrix et al., 1982; Bayliss et al., 1983; Broom and Poole, 1983; Orford and Gardner, 1984; Müller-Glauser et al., 1986; Mendler et al., 1989; Furuto et al., 1991; Poole et al., 1992; Wu et al., 1992; Hagiwara et al., 1993; Hedbom and Heinegárd, 1993; Wotton and Duance, 1994; Weber et al., 1996; Danielson et al., 1997; Hagg et al., 1998), the three dimensional structure of AC is still controversial, due to the variation in preparation methods, imaging techniques and the variety of species in which AC has been studied.

Hunter (1743) originally used a 'glas' to study AC. Since then light microscopy (Fawns and Landells, 1953; Anderson, 1961; Stockwell and Scott, 1967; Poole, 1970; Rosenberg, 1971; Shephard and Mitchell, 1976; Kincaid and Evander, 1985; Olivier et al., 2001; Hyllested et al., review, 2002), polarised light microscopy (Benninghoff, 1925; MacConail, 1951; Arokoski et al., 1996; Módis et al., 1996; Olivier et al., 2001), transmission electron microscopy (Anderson, 1964; Weiss et al., 1968; Minns and Stevens, 1977; Engfeldt et al., 1986; Broom, 1986; Jurvelin et al., 1996; Hunziker et al., 1996; Hunziker et al., 1997) and scanning electron microscopy (Inoue et al., 1969; Clarke, 1971; Clarke, 1974; Redler, 1974; Ghadially et al., 1975; 1977; Clark, 1990; Jeffery et al., 1991; Clark and Simonian, 1997; Kääb, 1998; Kääb et al., 1999; Clark et al., 1999; ap Gwynn et al., 2000; 2002), among other techniques, have all been employed in the attempt to determine the structure of AC. The ultrastructure of AC is an area still under debate and several different models of AC structure are described.

Benninghoff (1925) proposes a model for the structure of AC after using mechanical means to split the tissue as well as polarised light microscopy to observe in which directions the splits took place. This model suggests that the fibres in $\mathrm{AC}$ are arranged in a perpendicular orientation, with respect to the articular surface, in the deep or radial zone, before arching over in the intermediate or transitional zone. In the regions near the surface of the cartilage, the superficial or tangential zone, the fibres lie in a parallel orientation to the articular surface.

Other models for the structure of AC either build on and further develop Benninghoff's model, or dispute it. While many authors confirm the parallel alignment of fibres in the superficial zone of AC (Cameron and Robinson, 1958; McCall, 1962; Anderson, 1964; Silberberg et al., 1966; Clarke, 1971; Teshima et al., 1995), the situation in the intermediate and deep zones is more controversial. The arching of collagen fibres in the intermediate zone is described in a few papers subsequent to Benninghoffs (Clarke, 1971; Clark and Simonian, 1997) as well as suggestions that a more isotropic arrangement is present (Little et al., 1958; Hunziker, 1992). MacConnail (1951) employs polarised light microscopy as well as interference microscopy and reveals that $\mathrm{AC}$ comprised interweaving collagen fibres throughout the deep and intermediate zones, bounded at the surface by a "Lamina splendens", a bright line of tissue at the surface of the AC. Clark (1990) shows, using SEM, that rather than the arching collagen fibres interweaving as in Benninghoff's model, they form overlapping thin layers bending in a single direction.

The deep zone of AC is one of the most intensely studied regions of cartilage and is usually also the zone with the greatest volume (Hunziker, 1992). The radial or perpendicular orientation of the collagen fibres and fibrils, as presented in Benninghoff's model, is frequently observed (Little et al., 1958; McCall, 1962; Anderson, 1964; Clarke, 1971; Clark, 1990; Clarke and Simonian, 1997; Kääb, 1998; Kääb et al., 1998; ap Gwynn et al., 2000; 2002) However, there are studies that have shown that although the majority of fibrils may run perpendicularly, there is also a second group of fibrils, intersecting transverse fibrils, present in the radial/deep zone (Hunter, 1743; Hunziker et al., 1997; MacConaill, 1951; Bullough and Goodfellow, 1968). Random fibril orientation is also observed in the deep zone (Weiss et al., 1968). Hunziker et al., 1997 shows that the fibrils in this region are closely packed together with the banding on the fibrils in register. Other studies show that the fibrils lie not only aligned in a perpendicular direction but also may be arranged into tubule-like structures in the rabbit (Kääb, 1998; ap Gwynn et al., 2000; ap Gwynn et al., 2002). These structures correspond to the known biomechanical properties of the tissue and would act as a dampening system during compression by resisting lateral fluid flow in the tissue and directing it against the compressive force (ap Gwynn et al., 2002). However, there is an additional division of the matrix in the deep zone of AC into the territorial (TM) and interterritorial (IM) matrices, focussed around the chondrons (Clarke, 1974). This further division is rarely discussed in the literature and further complicates the construction of a model for AC structure.

Much of the controversy surrounding the structure of AC derives from the methods used for fixation of the tissue prior to imaging. Different chemical preparation methods produce different results (Hunziker et al., 1982; Kiviranta et al., 1984; Kääb et al., 1999;). Studies in more recent years focus on using cryo-fixation methods for electron microscopy to preserve tissue as close to the living state as possible (Studer et al., 1995; Hunziker et al., 1996; Hunziker et al., 1997; Eyre et al., 2002; ap Gwynn et al., 2000; 2002). Cryo-fixation techniques have led to new and in some cases novel ideas about the structure of AC in several species (Hunziker et al., 1996; Hunziker et al., 1997; Kääb, 1998; ap Gwynn et al., 2000, 2002).

Mouse AC has not been studied extensively with high-resolution imaging methods except with transmission electron microscopy (TEM), (Silberberg et al., 1961; 1964; 1966). Mouse AC appears to be an ideal subject for electron microscopic investigations due to the small size of the tissue, enabling the $\mathrm{AC}$ to be fixed whole while preserving its structural integrity as much as possible. The mouse also is an ideal model to use for studies of the development of $\mathrm{AC}$ due to the relatively short time it takes to mature. Advancements in knockout mice strain technology have led to the production of mice with cartilage collagen and proteoglycan mutations (Fassler et al., 1994; Jacenko and Olsen, 1995; Danielson et al., 1997; Aszódi et al., 2000; 
Young and $\mathrm{Xu}, 2001$; Hyttinen et al., 2001; Chakravarti 2002; Gill et al., 2002). However, an adequate structural description of normal mouse AC has yet to be presented.

A combination of imaging techniques, including polarised light microscopy (PLM) and field emission scanning electron microscopy (SEM), were used to reveal novel structural features in adult mouse AC that may have important implications for the biomechanical functionality of the tissue. Initial investigations into the structural development of mouse AC were also conducted.

\section{Materials and Methods}

Whole tibiae from adult and immature CD1 mice (Harlen, UK), sacrificed by pentobarbitone overdose, ranging in age from 1 to 21 days and 1 to 8 months old, were dissected and fixed within 30 minutes according to the following protocols. A separate study was carried out to determine optimal fixation procedures. All procedures were carried out at room temperature $\left(24-26^{\circ} \mathrm{C}\right)$ unless otherwise stated. All the samples prepared for light microscopy were fixed with $4 \%$ formaldehyde in $0.1 \mathrm{M}$ piperazine-1,4-bis-2-ethanesulfonic acid buffer (PIPES), pH8.5, for 24 hours.

\section{Cryofixation}

Immediately after dissection, tibiae were placed in $0.1 \mathrm{M}$ phosphate buffered saline (PBS), pH 7.3 (Oxoid Unipath Ltd, UK) for a period between 5 and 30 minutes to prevent drying of the tissue. The tibiae were blotted dry and plunge frozen in propane cooled with liquid nitrogen. The specimens were freeze substituted, using a Leica EM AFS freeze substitution unit, at $-80^{\circ} \mathrm{C}$ for a total of 10 days. The freeze substitution medium used for the initial 5 days was $59.8 \%$ acetone, $30 \%$ methanol, $10 \%$ acrolein and $0.2 \%$ tannic acid (Kääb, 1998). This initial procedure was followed by 5 days in $100 \%$ acetone before the samples were brought up to room temperature and underwent three more changes, 15 minutes each, of $100 \%$ acetone.

\section{Chemical fixation}

Immediately following dissection tibiae were fixed in $4 \%$ formaldehyde in 0.1M PIPES, pH8.5, for 24 hours. Samples to be imaged by electron microscopy were rinsed in PBS buffer ( $\mathrm{pH} 7.3$ ) before being dehydrated in an ascending, $70 \%, 80 \%, 90 \%$ and three changes of $100 \%$ (for $15 \mathrm{~min}$ utes each change), acetone series. Samples to be imaged by light microscopy were rinsed in $0.1 \mathrm{M}$ PBS buffer $(\mathrm{pH}$ 7.3), decalcified in 1\% ethylenediamine tetra-acetic acid (EDTA) in $0.1 \mathrm{M}$ PBS, for 7 days, changing the solution daily, and fully dehydrated in an ascending, 70\%, 80\%, 90\% and three changes of $100 \%$ (for 15 minutes each change), ethanol series.

\section{Chemical digestion}

Unfixed tibiae were digested chemically immediately after dissection in unbuffered $2 \%$ papain (Sigma, UK) at $60^{\circ} \mathrm{C}$ for 3 days, at which point, all the uncalcified $\mathrm{AC}$ appeared to have been removed. The tissue was then decalcified briefly in $10 \%$ EDTA for 12 minutes, rinsed in $0.1 \mathrm{M} \mathrm{PBS}(\mathrm{pH} 7.3$ ) and fully dehydrated in an ascending, 70\%, 80\%, 90\% and three changes of $100 \%$ (for 15 minutes each change), acetone series.

\section{Drying, fracturing and mounting for electron microscopy}

Following full dehydration or freeze substitution, the tibiae were critical point dried using liquid carbon dioxide in a standard critical point drier (E3000, Polaron, UK) with 20 minutes between each of the 4 flushes. Once dried, samples were placed in a fracture device (ap Gwynn et $a l ., 2002$ ), cooled with liquid nitrogen, fractured and brought up to room temperature in a sealed container that prevented moisture condensing onto the samples. The tibiae were mounted on aluminium stubs and were coated with $4 \mathrm{~nm}$ platinum/palladium (80/20) using a high-resolution sputter coater (Agar, UK).

\section{Embedding, sectioning and staining for light microscopy}

Following ethanol dehydration, samples were placed in 3 changes of $100 \%$ xylene for a minimum of 1 hour each change. The tibiae were then placed in 3 changes of melted paraffin wax, at a temperature of $60^{\circ} \mathrm{C}$, for a minimum of 1 hour each change, before being placed in a watch glass containing fresh wax, orientated and blocked by cooling the specimen rapidly. The blocked samples were stored at $4^{\circ} \mathrm{C}$ until sectioning. The tibiae were sectioned at a thickness of $7.5 \mu \mathrm{m}$ and the sections were mounted onto plain glass slides.

The staining protocol used was based on the original picrosirius red method (Sweat et al., 1964) with minor changes. The sections were de-waxed in three changes of $100 \%$ histoclear (National Diagnostics, USA), for 3 minutes each change. The sections were re-hydrated in a descending ethanol series, 2 changes of $100 \%$ followed by 1 change each of $90 \%$ and $70 \%$ for 3 minutes each change. Re-hydration of the sections was ensured by washing the sections for 10 minutes in ultra-high purity (UHP) water. The tibial sections were stained in $0.1 \%$ direct red 80 (Aldrich Chemical Company, UK), (also known as sirius red), in saturated picric acid (BDH Chemicals Ltd, UK) for 1 hour. The sections were rinsed quickly twice in $0.5 \%$ glacial acetic acid to remove excess stain. The samples were re-hydrated in an ascending ethanol series $(70 \%, 90 \%$ and 2 changes of $100 \%$ ethanol) before 3 changes in histoclear, each change for duration of 3 minutes. The sections were mounted permanently in DPX histological mountant (BDH Chemicals Ltd, UK) and covered with a coverslip. Slides were left to dry at room temperature overnight.

\section{Microscope operating conditions}

Tibiae for EM were imaged using a Hitachi S-4700II field emission scanning electron microscope using the upper secondary electron detector. The microscope was operated in ultra-high resolution mode at an accelerating voltage of $1.5 \mathrm{kV}$ and an emission current of $10 \mu \mathrm{A}$. The working distance varied and was recorded on each image. Red (L) and cyan(R) anaglyph stereo-pair images were created by taking two images of the same region on a specimen, the second image taken after the sample 
had been tilted eucentrically by $6-10^{\circ}$. The images were combined using Quartz PCI (version 5.10, Quartz imaging corporation, Canada). The three dimension model and profile analysis were produced from anaglyph stereo-pair images using Mex (2004, Alicona imaging, Austria) software package.

Sectioned material was examined using a Leitz laborlux 12 light microscope attached to a JVC TK-C1381 video camera from which stills were taken. Sectioned specimens were also examined with polarised light using a Zeiss Photomicroscope III from which images were recorded onto photographic film. The images were later transformed to a digital format following film processing.

\section{Results and Discussion}

The results of applying different methods to fix, prepare and image the adult mouse AC correlated with each other, although some methods resulted in better ultrastructural preservation of the collagen matrix. General examination of the full depth $\mathrm{AC}$ was conducted using low magnification methods (figure 1). High resolution imaging was used to examine, in detail, each of the four main histological zones.

\section{Tangential/superficial zone}

This zone was characterised by the parallel alignment of both the matrix and the chondrocytes to the articular surface. The articular surface appeared smooth with SEM and could be easily pulled off the underlying layers of collagen matrix during the fracture process. It was clearly identified as a bright line using polarised light microscopy of the picrosirius red stained tissue (figure 1). This structure was related to the "Lamina splendens" initially proposed by MacConaill (1951) and later identified by SEM (Clark, 1990). Immediately beneath the Lamina splendens were several layers of collagen fibrils, forming a mesh that ran parallel to the articular surface (figure 2). These layers appeared to extend to a depth of approximately $3 \mu \mathrm{m}$.

The chondrocytes in this zone, which appeared to be located beneath the layers of collagen fibrils, were the smallest observed in mouse articular cartilage, by both light and electron microscopy (figures 1 and 2). The chondrocytes were flattened along the axis parallel to the articular surface. In the fractured tissue, the chondrocytes only appeared singly, except in fractured samples where the collagen layers were peeled away - when paired chondrocytes were observed. The matrix surrounding the chondrocytes appeared uniform, with the collagen fibrils isotropically arranged with respect to one another, and was generally orientated parallel to the articular surface.

The superficial zone was the earliest zone to be expressed during development of mouse articular cartilage, present at 5 days in age (figure 8).

\section{Transitional/intermediate zone}

This zone could not be identified by polarised light microscopy, its absence in the images suggesting that the matrix of this zone was isotropically aligned (figure 1), only anisotropic structures can be detected by polarised light microscopy, even after being stained with picrosirius red. The only structures observed in this zone, by means of polarised light microscopy, were the pericellular capsules surrounding the chondrocytes, even after rotation and adjustment of the polarising filters.

The transitional zone, imaged using SEM, showed the matrix and cells arching over, from the perpendicular alignment, with respect to the articular surface, observed in the deep zone, to the parallel alignment of the superficial zone (figure 3). The collagen fibrils were isotropically arranged, as expected from the polarised light microscope results, and appeared to curve around the chondrocytes. The isotropy in the intermediate zone is also described elsewhere (Little et al., 1958; O’Conner et al., 1988; Hunziker, 1992).

The often paired chondrocytes, as observed with LM and SEM, were rounded in morphology and were orientated at an angle to the articular surface (figure 3). The intermediate zone appeared after the tissue developed parallel alignment of chondrocytes and matrix, giving the superficial zonation of the tissue. There was a reduction in the birefringence of the tissue in the load-bearing region of the developing AC, with paired chondrocytes appearing to be randomly arranged and at a variety of different angles to the articular surface. The intermediate zone appeared initially at approximately 7 days of age (figure 8).

\section{Radial/deep zone}

The deep zone was the largest zone, occupying 60-80\% of the uncalcified cartilage in the adult mouse. The chondrocytes were large and appeared rounded, almost identical to those observed in the intermediate zone, but were orientated perpendicularly to the articular surface (figure 4). The alignment of the chondrocytes was reflected in the collagen matrix, the fibrils of which were also mainly orientated perpendicularly to the articular surface. The collagen matrix in the deep zone was divided into to distinct regions, the territorial (TM) and interterritorial (IM) matrices (figure 5).

The TM appeared to surround the chondrons and was often visible even when the chondrocytes were not. When viewed with polarised light microscopy, the TM appeared extremely birefringent and was observed to extend from the deep zone through the 'tidemark' and down into the calcified zone, forming a continuum (figure 1). The appearance of the TM surrounding columns of chondrocytes was also seen by SEM (figure 4) and was observed to be arranged in a 'sheet-like' fashion after both formaldehyde and cryo-fixation (figure 5). Evidence for the sheet-like collagen network surrounding the chondrons was also seen following chemical digestion of the uncalcified regions of the AC (figure 7) - indicating that this is a natural feature of the deep zone.

The collagen sheets appeared to be formed mostly from perpendicularly orientated collagen fibrils, aligned so that the collagen banding was in register. The collagen banding was often particularly prominent and appeared to be separate structures, possibly orthogonally arranged fine fibrils connecting the main collagen fibrils (figure 5 ). On the surface of the matrix sheets some collagen fibrils appeared to emerge from the sheet, at an angle to the general orientation, before rejoining the matrix sheets some distance away. Such fibrils could form connections 

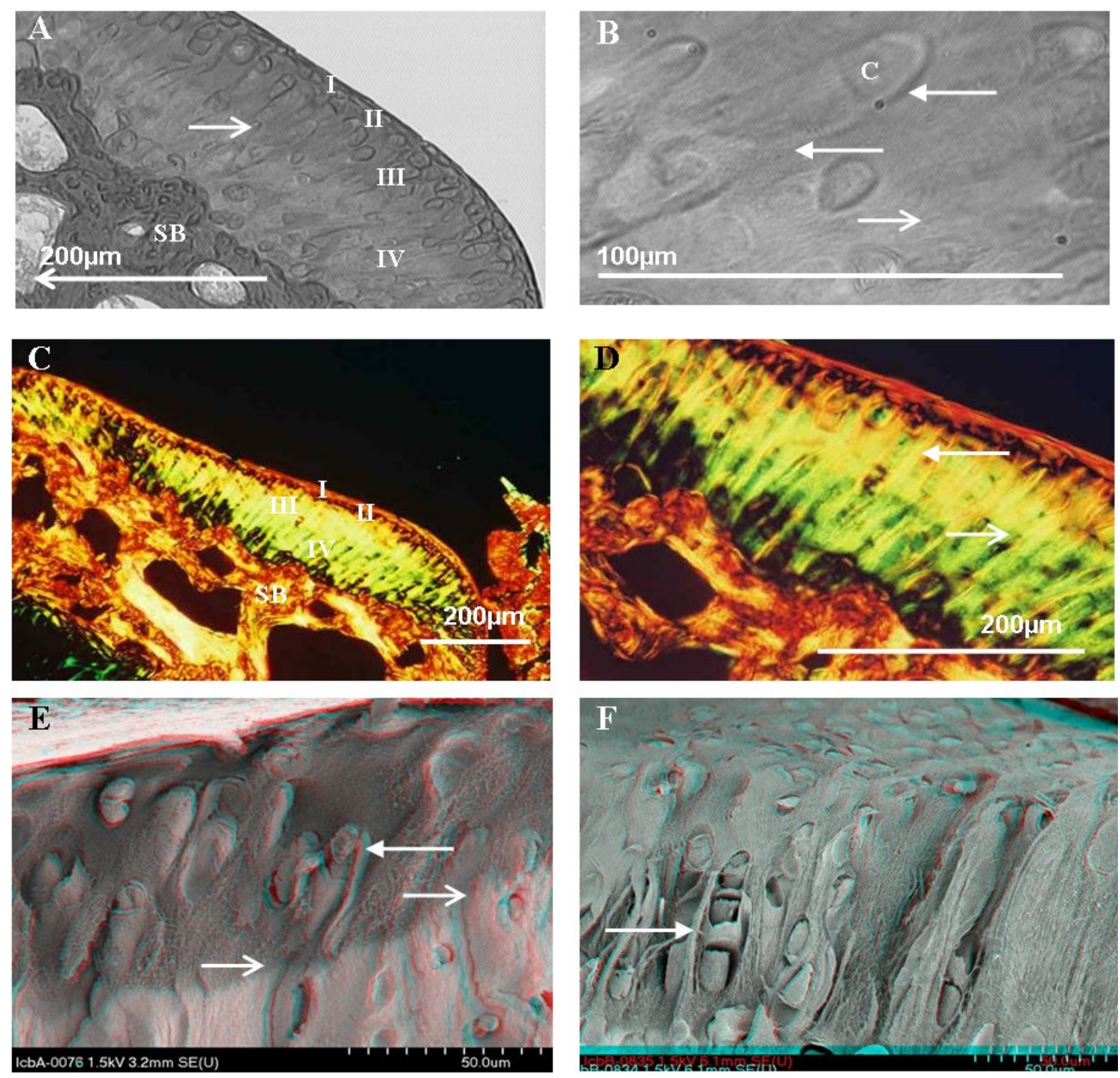

Figure 1. Adult mouse articular cartilage fixed either in formaldehyde (figures A-D) decalcified, embedded, sectioned, stained in picrosirius red and imaged by LM (figures A and B) and PLM (figures C and D), or cryofixed (figures E and F), dried, fractured and imaged by SEM to create red(L)-cyan $(\mathrm{R})$ anaglyph stereo-pair images $\left(6^{\circ}\right.$ tilt). The chondrocyte $(\mathrm{C})$ orientations indicate the zonation of the tissue in the LM images (figures A and B) and there are also clear zonal differences in the collagen matrix shown in the PLM images (figures C and D). I, II, III and IV indicate the positions of the superficial, intermediate, deep and calcified zones respectively and SB indicates the position of the subchondral bone. The tidemark boundary between the deep and calcified zones (open arrows) by each of the microscopic methods is clearly distinguished. More intensely stained (LM) and birefringent (PLM) regions of the collagen matrix can also be observed, located adjacent to the chondrocytes and their surrounding pericellular capsules and representing the regions of TM (closed arrows). The TM surrounds columns of cells, apparent in all the images. The SEM images (figures E and F) show both the matrix and chondrocyte orientations with the superficial zone arching over the deeper zones of the tissue (figure E) and lifted away, exposing the underlying chondrocytes (figure F). 

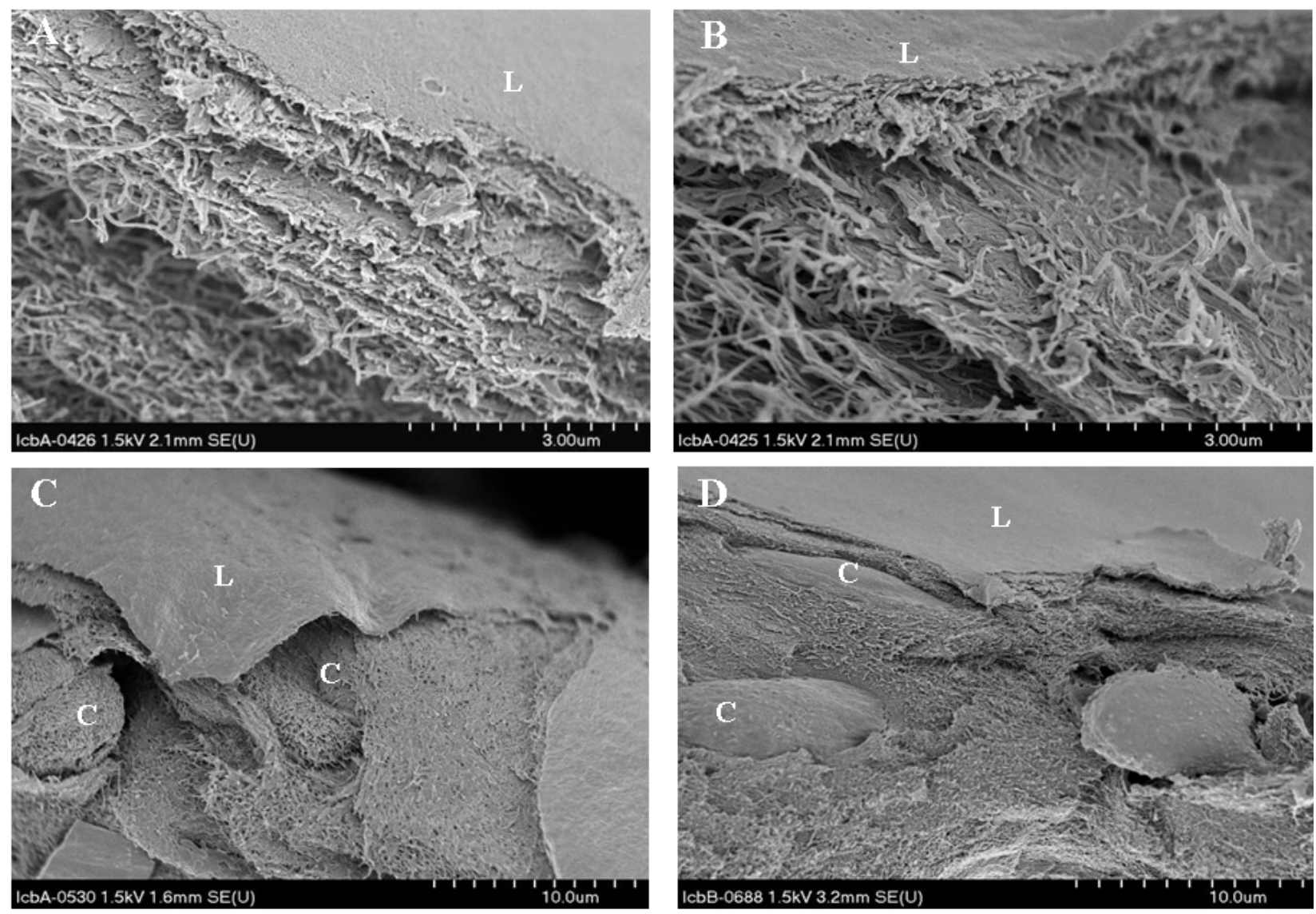

Figure 2. Legend on next page
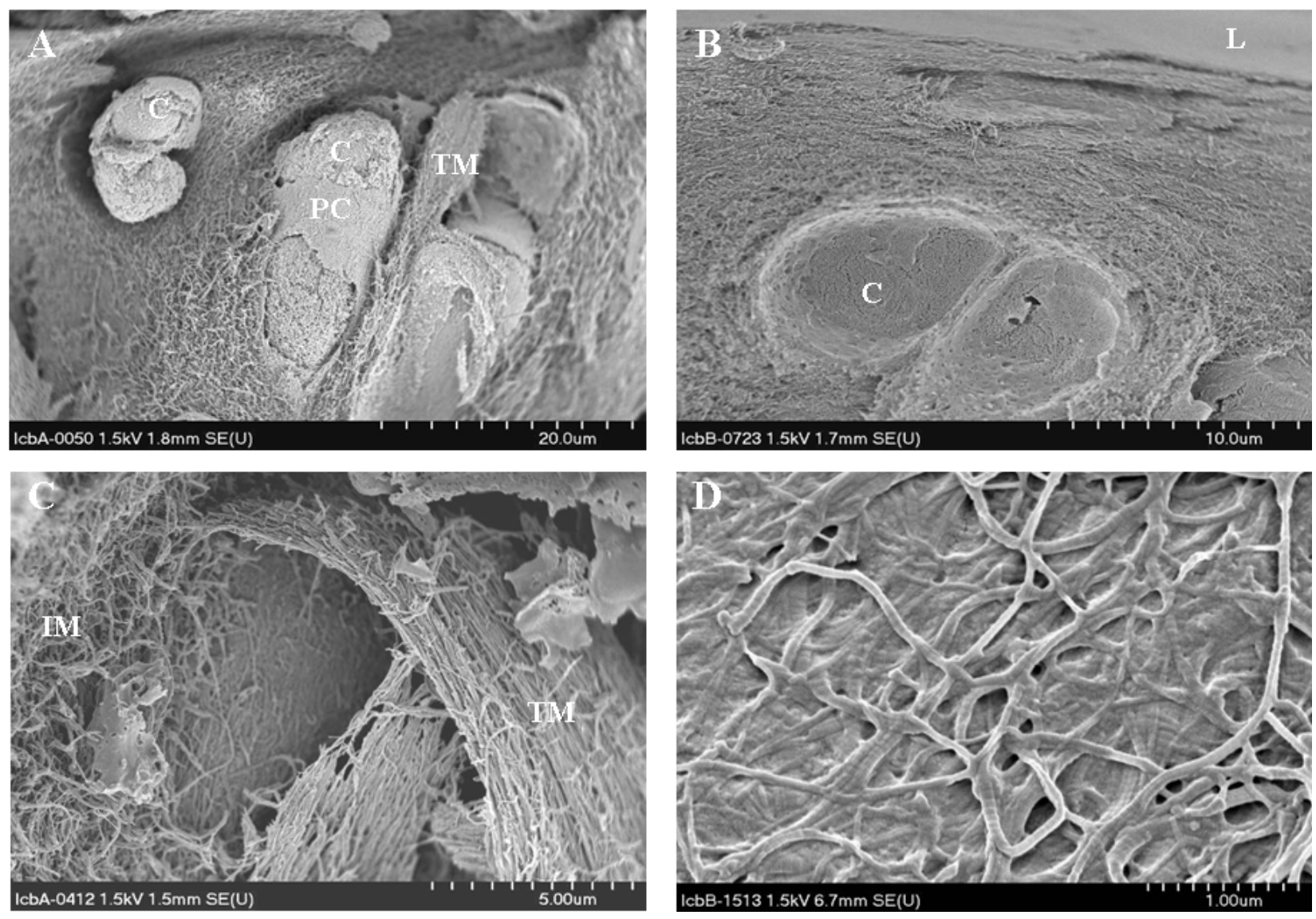

Figure 3. Legend on next page 
Figure 3. The transitional zone of adult mouse articular cartilage (figures A-D) either cryofixed (figures A and B) or fixed in formaldehyde (figures $\mathrm{C}$ and $\mathrm{D}$ ), dried, fractured and imaged by SEM. The chondrocytes (C, figures $\mathrm{A}$ and B), surrounded by their pericellular capsules (PC), are rounded in morphology, are at an angle to the articular surface and are located between the parallel chondrocytes in the superficial zone and the larger, perpendicular columns of chondrocytes of the deep zone. The territorial matrix (TM, figure C) arches over from the perpendicular deep zone to align with the parallel superficial zone. The TM is composed into sheet-like structures of randomly orientated collagen fibrils (figure D) and surrounds the chondrons in the intermediate zone. The interterritorial matrix (IM, figure C) is more isotropic and does not appear to have an overall orientation.

Figure 2. The superficial zone of adult mouse articular cartilage (figures A-D) fixed either in formaldehyde (figures $\mathrm{A}$ and $\mathrm{B}$ ) or cryofixed (figures $\mathrm{C}$ and D), dried, fractured and imaged by SEM. On the articular surface is located the "Lamina splendens" (L), a distinct membrane-like structure. Beneath the Lamina splendens are several layers (figures A and B) orientated parallel to the articular surface and appear to be composed of nets of interwoven collagen fibrils. Underneath the layer of collagen fibrils, at a depth of approximately $3 \mu \mathrm{m}$ are the superficial zone chondrocytes (C) surrounded by their pericellular capsules (figures $\mathrm{C}$ and D). The chondrocytes are flattened with respect to the articular surface.
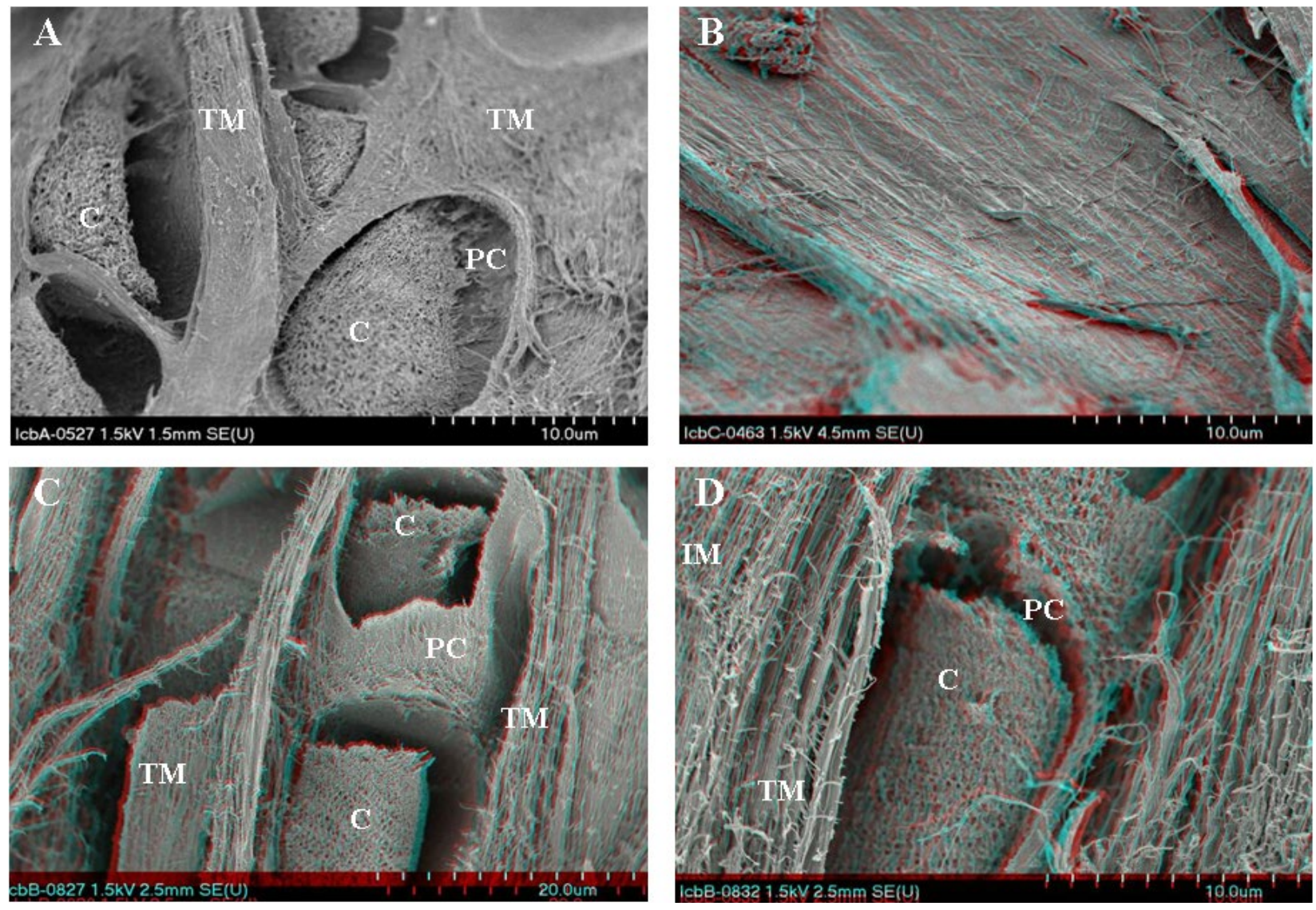

Figure 4. The deep zone of adult mouse articular cartilage (figures A-D), cryofixed, dried, fractured and imaged by SEM. Figures B, C and D are red(L)-cyan(R) anaglyph stereo-pairs. The chondrocytes $(\mathrm{C})$ in this zone were the largest observed in the tissue and are orientated perpendicularly to the articular surface. The lacuna between the chondrocytes and their pericellular capsules (PC) are artefacts caused by cell shrinkage during the critical point drying of the tissue. The chondrocytes are orientated into columns of cells surrounded by territorial matrix (TM) that appears to wrap itself around the pericellular capsules (figures A and C). Figure A shows a group of chondrocytes with clear bands of TM between the chondrons and surrounding the whole group. The curvature of the TM in a region where the chondrocyte and pericellular capsule are missing is shown in figure $\mathrm{B}$ and is also shown in figures $\mathrm{C}$ and $\mathrm{D}$ where the chondrons remain. 

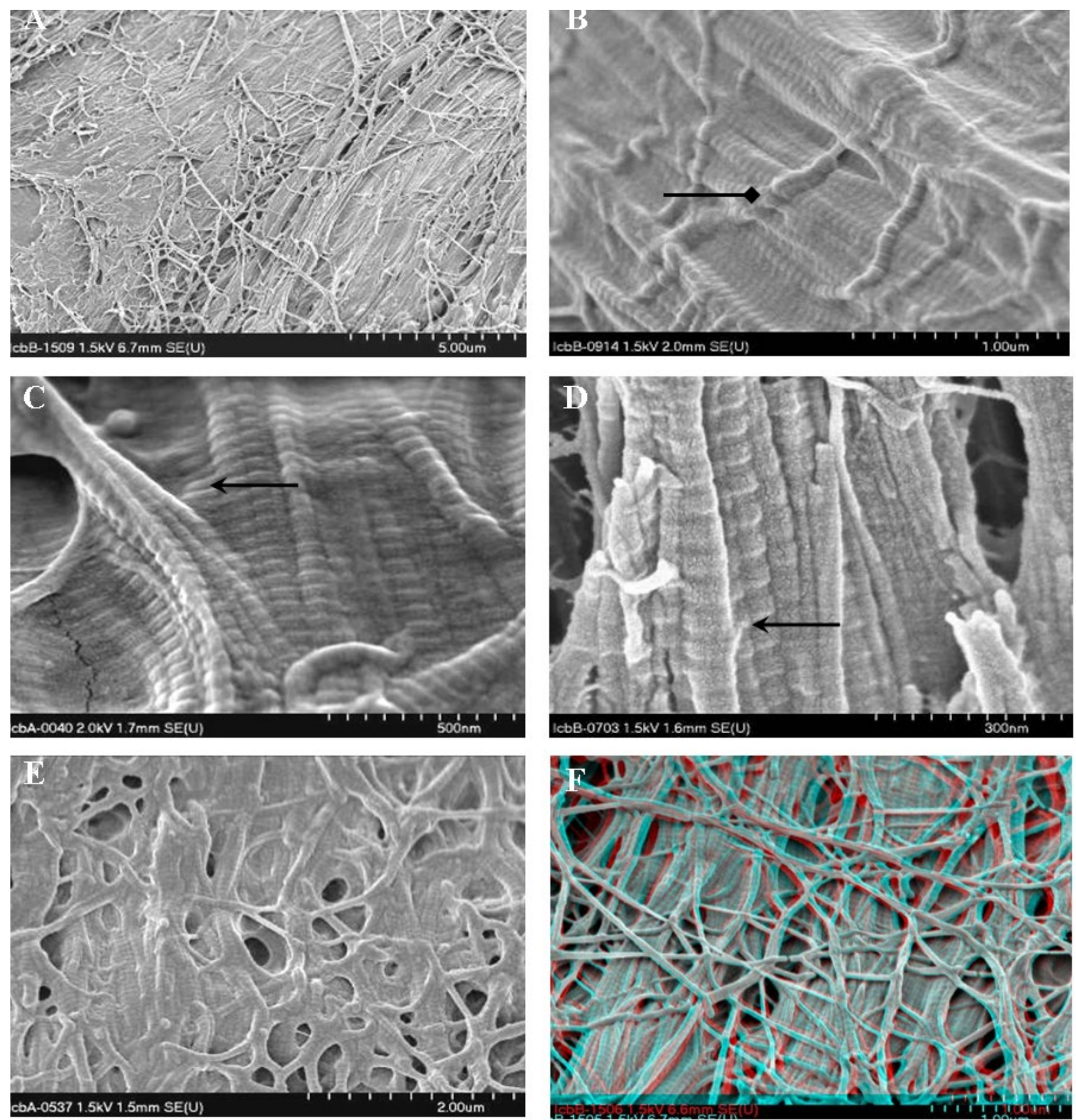

Figure 5. The different types of matrix in the deep zone of adult mouse articular cartilage, the territorial matrix (figures A-D) and the interterritorial matrix (figures E and F) either fixed in formaldehyde (figures A and F) or cryofixed (figures B-E), dried, fractured and imaged by SEM. The TM is clearly composed of collagen sheets with the majority of the collagen fibrils aligned parallel to one another and perpendicular to the articular surface (figures A-D). All the collagen fibrils exhibit a banding along their lengths and in the parallel sheet fibrils this is in register. In some regions the bands span between fibrils indicating that their may be an additional structure that binds the collagen fibrils in a spacing that corresponds to the D-periodic banding in collagen (arrows, figures $\mathrm{C}$ and D). There are also a number of collagen fibrils that are more isotropically arranged and weave in and out of the underlying collagen sheets (figures A, B and C, diamond shaped arrow). The banding on the fibrils weaving in and out of the matrix is apparent but appears slightly different to that observed on the sheet-like collagen fibrils. Figure D shows matrix slightly damaged by ice-crystals but still showing banding on the collagen fibrils. The interterritorial matrix is more isotropic (figures $\mathrm{E}$ and F). Figure F is a $\operatorname{red}(\mathrm{L})$-cyan(R) anaglyph stereo-pair. 

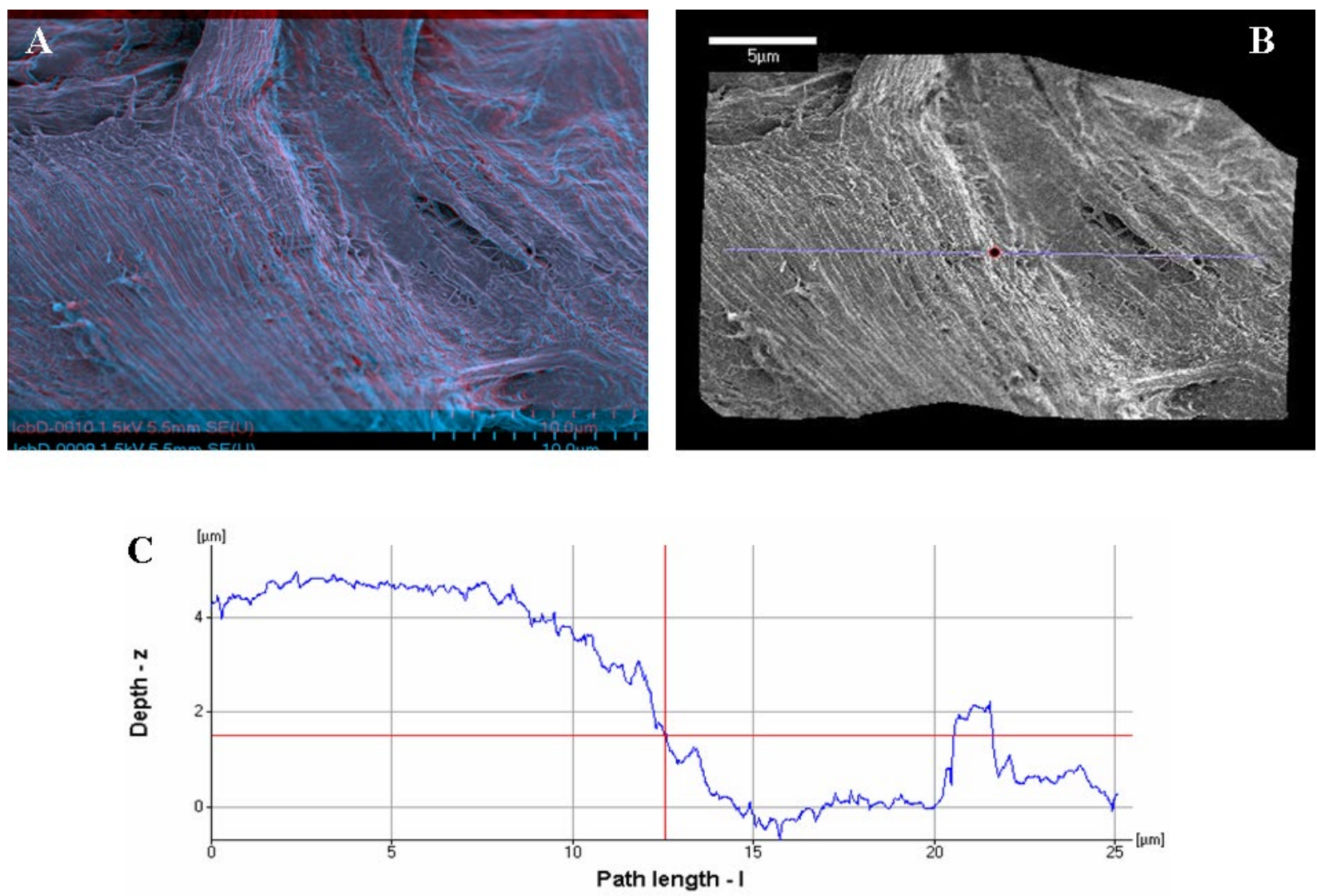

Figure 6. The collagen sheets in adult mouse articular cartilage (A-B), cryofixed, dried, fractured and imaged by SEM. Figure A shows a red(L)-cyan(R) anaglyph stereo-pair image of the collagen sheets as they appear on the fracture face. The three dimensional image shows how the collagens sheets undulate across the face of the fracture. Figure B shows an image of the three dimensional model constructed from the stereopair, also showing the undulation of the matrix. The purple line on figure B indicates the line along which the profile graph is constructed (figure C). The profile graph shows the representative height of the matrix from the lowest point on the model. It is possible to see how the collagen sheets have curved around chondrons. The fracture has propagated over a chondron on the left hand side of the images (figures A and B), resulting in a hill on the graph (figure C), whereas it appears to have gone under the adjacent chondron on the right hand side of the images (figures A and $\mathrm{B})$, creating a dip in the graph (figure C).

between the collagen sheets and also integrate the IM and the proteoglycans with the sheet-like structures observed. These collagen sheets are novel structures observed in the mouse AC. Similar arrangements of collagen fibrils are observed in rabbit, sheep and human AC, where the fibrils appear to be assembled into tubes containing the hydrated proteoglycans (Kääb, 1998; ap Gwynn et al., 2000; 2002). Alternatively, Hunziker and colleagues (1997) show regions in human $\mathrm{AC}$ where there are bundles of parallel collagen fibrils with the fibrillar banding in register and a secondary fibril network of more isotropically arranged collagen fibrils. As both the freezing and the fixation of the tissue by chemical methods revealed the collagen sheets, it is likely that they are not an artefact of the preparation methods and are related to the structures shown in other species.

While the collagen sheets were observed mainly surrounding the chondrons, there were cryofixed samples, in which no obvious damage due to ice-crystal formation was observed, that appeared to be constructed entirely from the sheet-like collagen matrix (figure 6). However, these images need careful interpretation, as during the process of fracturing, the fracture plane may propagate along the line of least resistance, resulting in an increased likelihood of collagen sheet exposure. The chemical digestion of the uncalcified regions of the $\mathrm{AC}$, exposing the upper edge of the calcified zone, the 'tidemark', revealed the high density of chondrocytes and chondrons within the tissue (figure 7). The chondrons were often very tightly packed together with only a relatively small amount of TM between them. It was mostly the TM that was exposed during the fracture process, resulting in the appearance of a continuous sheetlike appearance of the collagen matrix with very few cells observed (figure 6). Examination of the collagen sheets, using three dimensional models built from anaglyph stereo-pair images and profile analysis of the models (figure 6 ), revealed that the exposed matrix curved significantly around structures that had the same dimensions as chondrons.

The observation regarding cellular density in the tissue contrasts with that in other species where the IM appears to form most of the deep zone cartilage (Hunziker et al., 

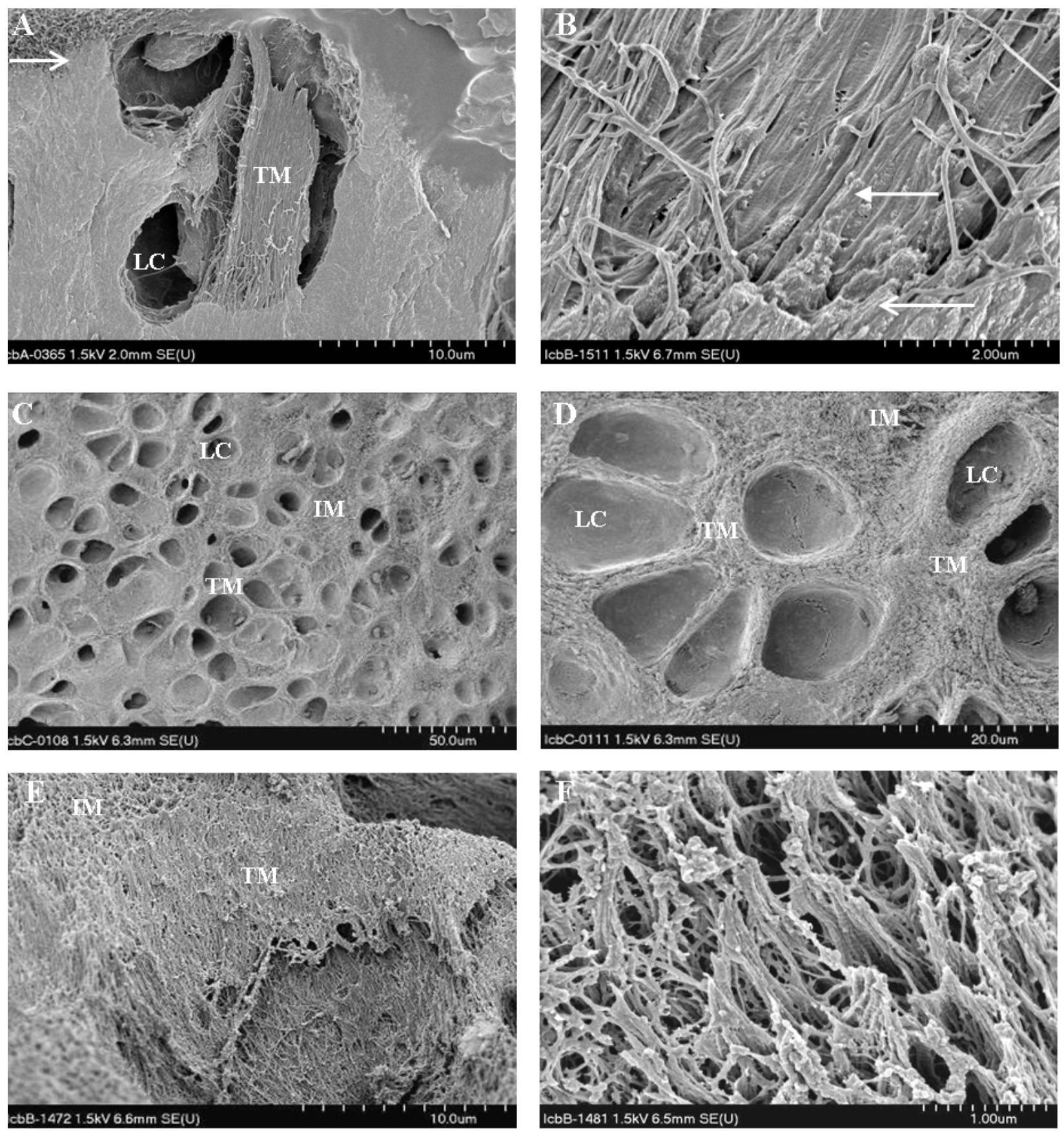

Figure 7. The calcified zone of adult mouse articular cartilage (A-F), either cryofixed (figure A), or fixed in formaldehyde (figure B), dried and fractured and imaged with SEM or with the uncalcified cartilage removed chemically (exposing the tidemark), decalcified, dried and imaged from above by SEM (figures C-F). The territorial matrix (TM) continues into to the calcified cartilage, through the tidemark (open arrows, figure A and B) surrounding the chondrocytes (figure A) and can be observed to show calcification extending up and along the collagen fibrils in the deep zone (closed arrow, figure B). The decalcification of the tissue, to expose the tidemark, shows that the chondrons span across the front of calcification and extend into the calcified zone, leaving lacunae (LC) to indicate the location of the cells and their pericellular matrices. The exposure of the tidemark also reveals how densely packed the mouse $\mathrm{AC}$ is with chondrons and that most of the remaining matrix is TM (figure $\mathrm{C}$ and D) with very little interterritorial matrix (IM) present. Closer examination of the tissue shows that the TM is composed of collagen sheets (TM, figure E), while the IM is more isotropic (IM, figures E and F). 

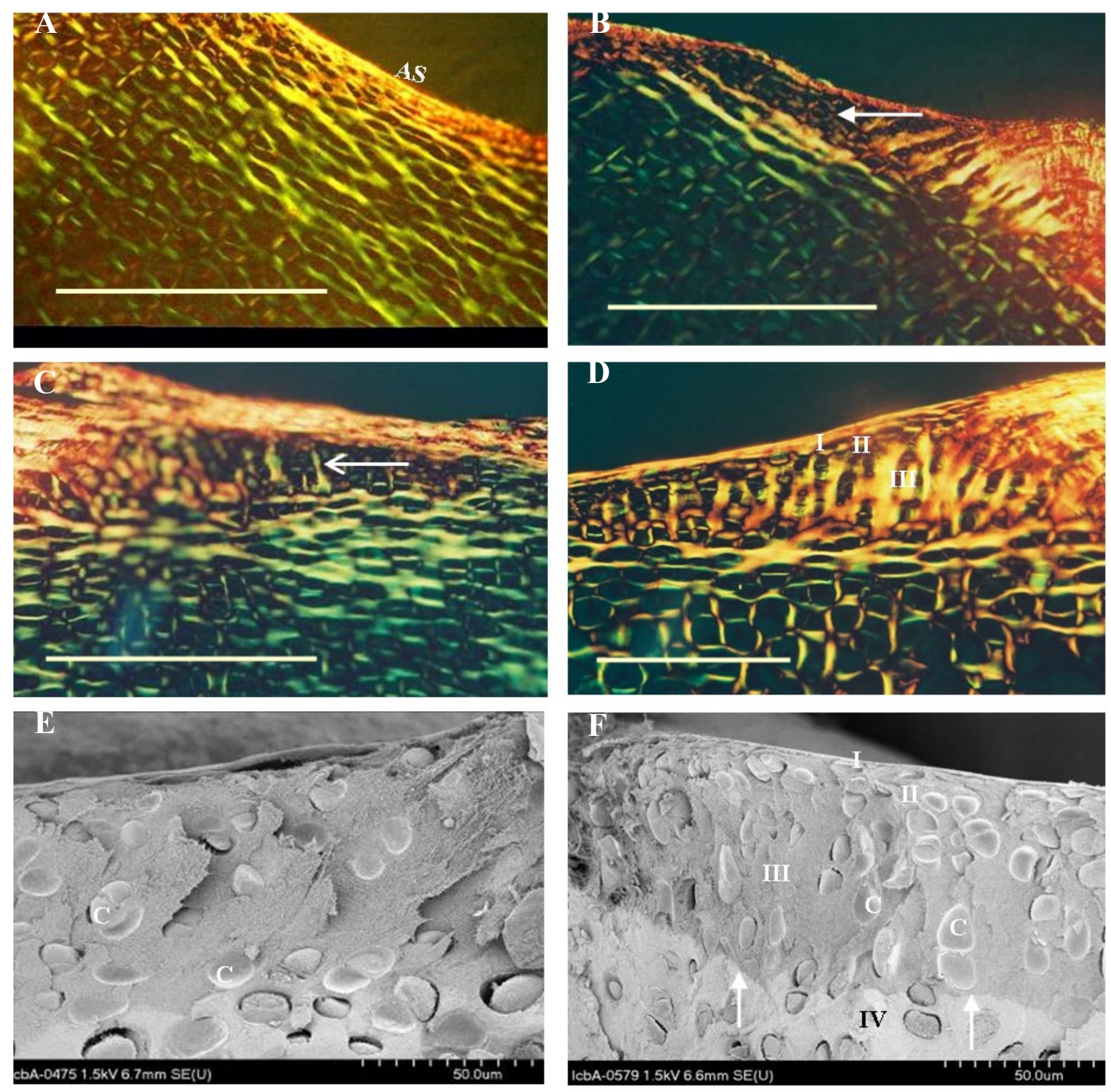

Figure 8. Developmental stages of mouse articular cartilage (A-F), fixed in formaldehyde, decalcified, embedded, sectioned, stained in picrosirius red and imaged by PLM (figures A-D), or cryofixed (figures E and F), dried, fractured and imaged by SEM. The scale bars represent $200 \mu \mathrm{m}$ (figures A-D). The orientation of the birefringent collagen fibres is initially parallel to the articular surface (AS) and extends to a depth of approximately $150 \mu \mathrm{m}$ (figure A) in 5 day old tissue. By 7 days in age the tissue shows a distinct region devoid of birefringence (closed arrow, figure B) and bordered two regions of birefringent collagen fibres that are orientated parallel to the articular surface. A region of developing perpendicular orientation occurs in the load-bearing region within days (open arrow, figure $\mathrm{C}$ showing 8 day old tissue) and shows extensive development and zonation of the cartilage by 12 days old (figure D). I, II, III and IV indicate the location of the superficial, intermediate, deep and calcified zones respectively (figures D and F). The chondrocytes (C) and matrix, in the 14 day old tissue (figure E), are similar, albeit slanted towards the centre of the joint, to the adult tissue, however, the calcified matrix is not very clear and the tidemark is very indistinct. By 18 days old the tissue cannot be distinguished from adult AC and the tidemark can easily be identified (vertical closed arrows, figure F). 
1997). However, there is variation in the cell density across species, related to the thickness of the AC rather than body weight, with mouse showing the greatest density of chondrocytes (Stockwell, 1971). The variation in cell density in relation to the thickness of the cartilage is a matter to be considered when comparing mouse AC to that of other species and would account for the structural variations observed. The rabbit 'tubular' arrangement being a possible derivation of structures homologous to the mouse collagen sheets, but where the matrix surrounding the chondrons is much thicker.

Extensive exposure of the chondrons (figures 1 and 4) only occurred after the tissue was compromised in some manner, i.e. with ice crystal formation. The damage caused by the small ice-crystals could only be observed at high magnification and did not effect the general orientation or zonation of the collagen matrix. Collagen sheets were only observed in samples with no evidence of ice-crystal damage or in chemically fixed samples.

The IM was mostly observed in the formaldehyde fixed tissue (figure 5). Generally, the matrix was orientated perpendicularly with respect to the articular surface. However, unlike in the TM, the collagen fibrils were not closely attached together in a highly organised manner, but instead were more isotropically arranged, agreeing with the AC appearance from other species (Hunziker et al., 1996; 1997). This appearance of the matrix was also observed following chemical digestion in the few regions of IM present.

The deep zone did not appear in the AC until the mice had reached approximately 8-9 days in age, as viewed with both light and polarised light microscopy (figure 8). The deep zone appeared to form within an intermediate zone space that was surrounded by the birefringent fibres orientated parallel to the articular surface. At this stage, both chondrons and collagen fibres started to be orientated perpendicularly to the articular surface in the load-bearing region of the tissue.

\section{Calcified zone}

The TM in the calcified zone was continuous with the TM in the deep zone in mouse AC, when observed by polarised light microscopy (figure 1). The tidemark, the calcification front, was not a specific structure but was used to describe the distinct line of transition in the AC matrix from the deep zone to the calcified zone. The calcification of the collagen fibrils was observed at the base of the deep zone, and apart from the obvious deposits along the length of the collagen fibrils, in the fractured tissue, imaged by SEM, the collagen matrix retained its structural integrity through both zones (figure 7).

The un-calcified regions of the $\mathrm{AC}$, the superficial, intermediate and deep zones, were digested chemically with the aim of exposing the tidemark of the calcified zone. The tissue was then decalcified briefly to expose the organisation of the collagen fibrils that had been preserved during the process of calcification and that were usually hidden in the tissue. The distinct TM and IM were immediately apparent, as was the high cellular density of the tissue, confirming the observations made concerning the structure of the collagen matrix in the deep zone (figure 7).
The calcified zone was the last zone to form and could not positively be identified using the techniques described, until the mice were just under 3 weeks old, when there was a marked change between the densities of the deep and calcified zones, as viewed with SEM (figure 8).

\section{A model of mouse AC}

A model has been proposed to integrate all of the components observed in the mouse AC (figure 9). In this model, the chondrons (the chondrocytes and their surrounding pericellular capsules) are aligned into continuous columns traversing the calcified and deep zone of the cartilage. A columnar arrangement of the cells was observed after PLM and SEM imaging of the tissue. In the PLM images the TM was continuous along the length of the cellular columns. In SEM, the TM was observed to curve around the chondrons (figure 4). In the model, the TM forms a tube around the chondrons - isolating and protecting the chondron units from the deformation of the AC. It would also limit or prevent lateral fluid flow across the collagen matrix that forms the TM. The IM appeared more isotropic, by all of the imaging and preparation techniques employed, and would probably undergo the greatest deformation during loading (figure 10).

Deformation of both the collagen matrix and the chondrocytes is observed during loading, but crucially only in the superficial and transitional zones; chondrocytes in the deep zones of rabbit AC do not appear to undergo any significant deformation (Guilak et al., 1995; Kääb et al., 1998; 2000; 2003). During the deformation of the tissue under load, the rigid collagen sheets that form the TM would protect the vulnerable chondrocytes and possibly direct or limit the amount of stimulation the cells are subjected to. Chondrocytes are affected by mechanical stimulus (Urban, 1994) and there are marked differences in the proliferation, cell cycle and metabolic rates of chondrocytes in various histological zones (Mankin 1962; 1964; Meachim and Stockwell, 1979; Hayes et al., 2001; Dowthwaite et al., 2004). In addition, the biomechanical properties of cartilage suggest the type of matrix arrangement suggested in the model, with a directed fluid flow acting against the compressive force, through "matrix pores" or "flow channels", the latter thought to help create the initial perpendicular alignment of the matrix (Zarek and Edwards, 1963; Armstrong and Mow, 1982; Tepic and Ito, 1997). The model would, thus, correlate with a number of investigations and the apparent early development of the tissue from the intermediate zone (figure 8) would, therefore, be logical.

The continuation of the cellular columns into and through the calcified zone is due to the progressive calcification of the uncalcified cartilage at the tidemark. The calcification of the tissue is uninterrupted throughout adult life and the calcified zone remains at a constant thickness, due mostly to the corresponding absorption of the calcified cartilage into the subchondral bone by endochondral ossification (Lane and Bullough, 1980; Bullough and Jagannath, 1983). Although the presence of the columns traversing the zones may be incidental, it would also function to help anchor the uncalcified tissue more firmly and strengthening 


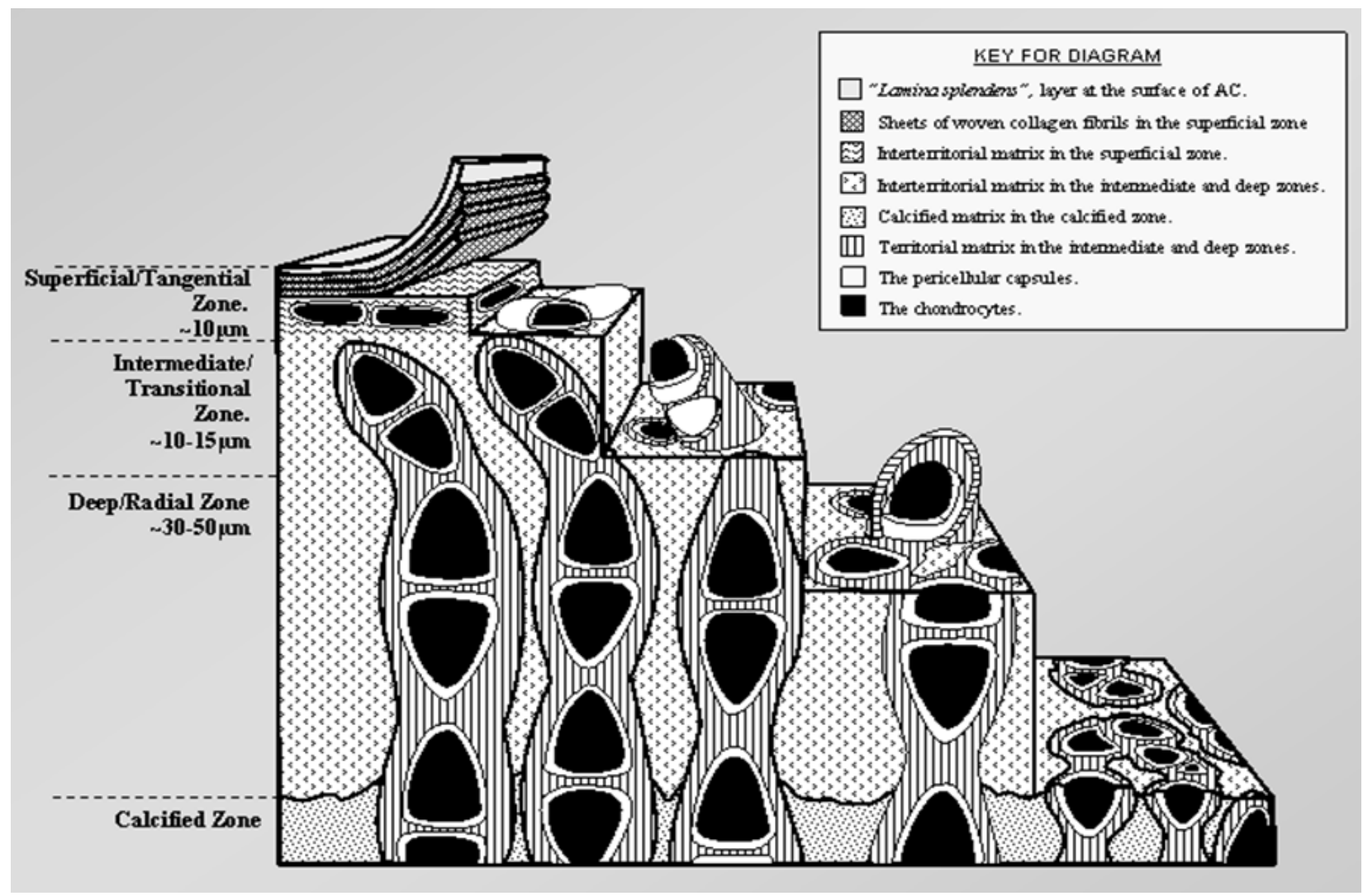

Figure 9. A diagrammatic model of mouse articular cartilage showing cut away sections of the different histological zones. The superficial zone is composed of layers of collagen fibrils beneath the Lamina splendens at the surface. Beneath the collagen layers the flattened superficial zone chondrocytes are surrounded by their pericellular capsules and an isotropic matrix orientated parallel to the articular surface. The chondrocytes in the intermediate zone are orientated at an angle to the surface and are surrounded by their pericellular capsules and territorial matrix composed of sheets of collagen fibrils aligned isotropically. The chondrocytes in the deep zone are orientated perpendicular to the articulating surface
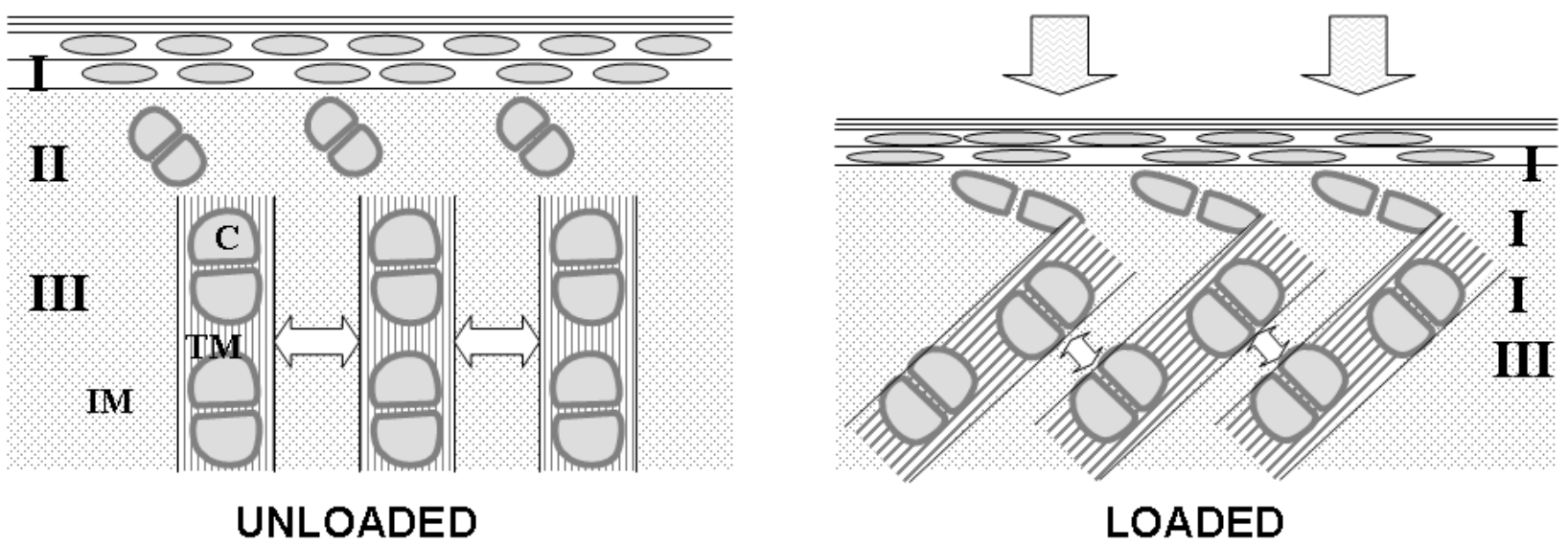

Figure 10. A diagram to illustrate the effects of loading on the different types of matrix as described in the model of mouse articular cartilage. Figure A shows the unloaded matrix appearance with all of the uncalcified histological zones represented. I, II an III indicate the superficial, intermediate and deep zones respectively. In figure B load has been applying resulting in the deformation of the superficial and transitional zone chondrocytes $(\mathrm{C})$ and matrix, while the chondrocytes surrounded and protected to a greater extent by the territorial matrix (TM) are relatively unchanged. The main deformation that occurs in the deep zone is in the interterritorial matrix (IM), allowing the cellular columns to slide over and with respect to one another. 
the region of the tidemark, the weakest point of the cartilage (Fawns and Landells, 1953; Otterness et al., 1999).

In the proposed model, it is clear that the chondrocytes occupy a central role in determining the structure of the cartilage. The role of chondrocytes beyond initially producing the matrix and the maintenance of cellular viability, although apparent, remains unclear. It is possible that the cells have an additional function in mediating the calcification of the tissue at a certain position or time.

The model of mouse AC has been developed after extensive examination of numerous samples using a variety of different fixation methods. Both chemical fixation and cryofixation methods have shown the same structures, collagen sheets surrounding columns of chondrocytes. Different imaging and preparation methods have led to the same conclusions, indicating that the presence of these structures are both continuous throughout the deep and calcified zones and that they are less likely to be the result of artefact formation. The model is in agreement with known biomechanical properties of this tissue and the way the tissue develops. How this model of cartilage relates to the situation in other species has yet to be determined.

\section{Acknowledgements}

This work was supported by Smith and Nephew Research, York.

\section{References}

Anderson CE (1964) The structure and function of cartilage. J Bone Joint Surg Am 44: 777-786.

Anderson H (1961) Histochemical studies on the histogenesis of the knee joint and superior tibia-fibular joint in human foetuses. Acta Anatomica 46: 279-303 + plate.

ap Gwynn I, Wade S, Ito K, Richards RG. (2002). Novel aspects to the structure of rabbit articular cartilage. Eur Cell Mater 2: 18-29.

ap Gwynn I, Wade S, Kääb MJ, Owen GRh, Richards RG (2000) Freeze-substitution of rabbit tibial articular cartilage reveals that radial zone collagen fibres are tubules. J Microsc 197: 159-172.

Armstrong CG, Mow VC (1982) Variations in the intrinsic mechanical properties of human articular cartilage with age, degeneration and water content. J Bone Joint Surg Am 64: 88-94.

Aszódi A, Bateman JF, Gustafsson E, Boot-Handerford R, Fässler R (2000) Mammalian skeletogenesis and extracellular matrix; what can we learn from knockout mice? Cell Struct Funct 25: 73-84.

Bank RA, Soudry M, Maroudas A, Mizrahi J, TeKoppele JM (2000) The increased swelling and instant deformation of osteoarthritic cartilage is highly correlated with collagen degradation. Arthritis Rheum 43: 2202-2210.

Basser PJ, Schneiderman R, Bank RA, Wachtel E, Maroudas A (1998) Mechanical properties of the collagen network in human articular cartilage as measured by osmotic stress technique. Arch Biochem Biophys 351: 207-219.
Bayliss MT, Venn M, Maroudas A, Ali SY (1983) Structure of proteoglycans from different layers of human articular cartilage. Biochem J 209: 387-400.

Benninghoff A (1925) Form und bau der Gelenknorpel in ihren Beziehungen zur Funktion. Z Zellforsch 2: 783862 .

Broom ND (1986). The collagenous architecture of articular cartilage - a synthesis of ultrastructure and mechanical function. J Rheumatol 13: 142-152.

Broom ND (1998) An enzymatically induced structural transformation in articular cartilage. Its significance with respect to matrix breakdown. Arthritis Rheum 31: 210-218.

Broom ND, Poole A (1983) Articular cartilage collagen and proteoglycans. Their functional interdependency. Structure - function studies of articular cartilage. Arthritis Rheum 26: 1111-1119.

Bullough PG, Goodfellow J (1968) The significance of the fine structure of articular cartilage. J Bone Joint Surg 50: $852-857$.

Bullough PG, Jagannath A (1983) The morphology of the calcification front in articular cartilage. J Bone Joint Surg Br 65: 72-78.

Burgesson RE, Nimni ME (1992) Collagen types. Molecular structure and tissue distribution. Clin Orthop 282: 250-272.

Cameron DA, Robinson RA (1958) Electron microscopy of the epiphyseal and articular cartilage matrix in the femur of the newborn infant. J Bone Joint Surg Am 40: 163-170.

Chakravarti S (2002) Functions of lumican and fibromodulin: lessons from knockout mice. Glycocoj J 19: 287-293.

Clark JM (1990) The organisation of collagen fibrils in the superficial zones of articular cartilage. J Anat 171: 117-130.

Clark JM, Simonian PT (1997) Scanning electron microscopy of "fibrillated" and "malacic" human articular cartilage: technical considerations. Micros Res Tech 37: 299-313.

Clark JM, Norman AG, Kääb MJ, Nötzli HP (1999) The surface contour of articular cartilage in an intact, loaded joint. J Anat 195: 45-56.

Clarke IC (1971) Articular cartilage: a review and scanning electron microscope study. 1. The interterritorial fibrillar architecture. J Bone Joint Surg Br 53: 733-750.

Clarke IC (1974) Articular cartilage: a review and scanning electron microscope study. II. The territorial fibrillar architecture. J Anat 118: 261-280.

Danielson KG, Baribault H, Holmes DF, Graham H, Kadler KE, Iozzo V (1997) Targeted disruption of decorin leads to abnormal collagen fibril morphology and skin fragility. J Cell Biol 136: 729-743.

Dowthwaite GP, Bishpo JC, Redmen SN, Khan IM, Rooney P, Evans DJR, Haughton L, Bayram Z, Boyer S, Thompson B, Wolfe MS, Archer CW (2004) The surface of articular cartilage contains a progenitor cell population. J Cell Sci 117: 889-897.

Engfeldt B, Hultenby K, Müller M (1986) Ultrastructure of hyaline cartilage. Acta Path Microbiol Immunol Scand Sect A 94: 313-323. 
Eyre D (2002) Collagen of articular cartilage. Arthritis Res 4: 30-35.

Eyre DR, Apon S, Wu JJ, Ericsson LH, Walsh KA (1987b) Collagen type IX: evidence for covalent linkages to type II collagen in cartilage. FEBS Lett 220: 337-341.

Eyre DR, Wu JJ, Apone S (1987a) A growing family of collagens in articular cartilage: identification of 5 genetically distinct types. J Rheumatol 14: 25-27.

Fassler R, Schnegelsberg PN, Dausman J, Shinya T, Muragaki Y, McCarthy MT, Olsen BR, Jaenisch R (1994) Mice lacking alpha 1 (IX) collagen develop noninflammatory degenerative joint disease. Proc Natl Acad Sci USA 91: 5070-5074.

Fawns HT, Landells JW (1953) Histochemical studies of rheumatic conditions. I. Observations on the fine structures of the matrix of normal bone and cartilage. Ann Rheum Dis 12: 105-113.

Furito DK, Gay RE, Stewart TE, Miller EJ, Gay S (1991) Immunolocalisation of types V and XI collagen in cartilage using monoclonal antibodies. Matrix 11: 144-149.

Ghadially FN, Ghadially JA, Oryschak AF, Yong NK (1975) Experimental production of ridges on rabbit articular cartilage: a scanning electron microscope study. J Anat 121: 119-132.

Ghadially FN, Ghadially JA, Oryschak AF, Yong NK (1977) The surface of dog articular cartilage: a scanning electron microscope study. J Anat 123: 527-536.

Gill MR, Oldberg A, Reinholt FP (2002). Fibromodulin-null murine knee joints display increased incidences of osteoarthritis and alterations in tissue biochemistry. Osteoarthritis Cartilage 10: 751-757.

Guilak FA, Ratcliffe A, Mow VC (1995) Chondrocyte deformation and local tissue strain in articular cartilage. A Confocal microscopy study. J Othop Res 13: 410-421.

Hagg R, Bruckner P, Hedbom E (1998) Cartilage fibrils of mammals are biochemically heterogeneous: differential distribution of decorin and collagen IX. J Cell Biol 142: 285-94.

Hagg R, Hedbom E, Möllers U, Aszódi A, Fässler R, Bruckner P (1997) Absence of the $\alpha 1$ (IX) chain lead to a functional knockout of the entire collage IX protein in mice. J Biol Chem 727: 20650-20654.

Hagiwara H, Schröter-Kermani C, Merker HJ (1993) Localisation of collagen type VI in articular cartilage of young and adult mice. Cell Tissue Res 272: 155-160.

Hascall VC, Hascall GK (1981) Proteoglycans. In: Hay ED, ed. Cell biology of extracellular matrix. Plenum Press, London. 39-63.

Hayes AJ, MacPherson S, Morrison H, Dowthwaite G, Archer CW (2001) The development of articular cartilage: evidence for an appositional growth mechanism. Anat Embryol (Berl) 203: 469-479.

Hedbom E, Heinegård D (1993) Binding of fibromodulin and decorin to separate sites on fibrillar collagens. J Biol Chem 268: 27307-27312.

Hendrix MJC, Hay ED, Van der Mark K, Linsenmeyer TF (1982) Immunohistochemical localisation of collagen types I and II in the developing chick cornea and tibia by electron microscopy. Invest Ophthalmol Vis Sci 22: 359375 .
Huang X, Birk DE, Goetinick PF (1999) Mice acking in matrilin-1 (cartilage matrix protein) have alterations in type II collagen fibrillogenesis and fibril organisation. Dev Dyn 216: 434-441.

Hunter W (1743) On the structure and diseases of articulating cartilages. Philos Trans R Soc Lond 42: 514-521.

Hunziker EB (1992) Artilcular cartilage structure in humans and experimental animals. In. Articular cartilage and osteoarthritis. (eds Kuttener K, Schleyerbach H R, Peyron JG, Hascall VC). Raven Press, New York. 183-199.

Hunziker EB, Herrmann W, Schenk RK (1982) Improved cartilage fixation by ruthenium hexamine trichloride (RHT). A prerequisite for morphometry in growth cartilage. J Ultrastruc Res 81: 1-12.

Hunziker EB, Michel M, Studer D (1997) Ultrastructure of adult human articular matrix after cryotechnical processing. Microsc Res Tech 37: 271-284.

Hunziker EB, Wagner J, Studer D (1996) Vitified articular cartilage reveals novel ultrastructural features respecting extracellular matrix architecture. Histochem Cell Biol 106: 375-382.

Hyllested JL, Veje K, Ostergaard K (2002) Histochemical studies of the extracellular matrix of human articular cartilage - a review. Osteoarthritis and Cartilage 10: 333343.

Hyttinen MM, Töyräs T Lapveteläinen T, Lindblom J, Prockop D, Li SW, Arita M, Jurvelin JS, Helminen HJ (2001) Inactivation of one allele of the type II collagen gene alters the collagen network in murine articular cartilage and makes cartilage softer. Ann Rheum Dis 60: 626-628.

Inoue H, Kodama T, Fujita T (1969) Scanning electron microscopy of normal and rheumatoid articular cartilages. Arch Histol Jap 30: 425-435.

Iozzo AD, Murdoch AV (1996) Proteoglycans of the extracellular environment: clues from the gene and protein side offer novel perspectives in molecular diversity and function. FASEB J 10: 598-614.

Jacenko O, Olsen BR (1995) Transgenic mouse models in studies on skeletal disease. J Rheumatol 22: 39-41.

Jeffery AK, Blunn GW, Archer CW, Bentley G (1991) Three-dimensional collagen architecture in bovine articular cartilage. J Bone Joint Surg Br 73: 795-801.

Jurvelin JS, Müller DJ, Wong M, Studer D, Engel A, Hunziker EB (1996) Surface and subsurface morphology of bovine humeral articular cartilage as assessed by atomic force and transmission electron microscopy. J Structural Biol 117: 45-54.

Kääb M (1998) The deformation of articular cartilage collagen structure under mechanical load. PhD Thesis. University of Wales.

Kääb MJ, Ito K, Clark JM, Nötzli HP (1998) Deformation of artilcar cartilage collagen structure under static and cylic loading. J Orthop Res 16: 743-751.

Kääb MJ, ap Gwynn I, Nötzli HP (1998) Collagen fibre arrangement in the tibial plateau articular cartilage of man and other mammalian species. J Anat 193: 23-34.

Kääb M J, Richards R G, Walther P, ap Gwynn I, Nötzli H P (1999) A Comparison of four preparation methods for the morphological study of articular cartilage for scanning electron microscopy. Scanning Microscopy 13: 61-70. 
Kääb MJ, Ito K, Rahn B, Clark J, Nötzli H (2000). Effect of mechanical load on articular cartilage collagen structure. A scanning electron microscope study. Cells Tissues Organs 167: 106-120.

Kääb MJ, Richards RG, Ito K, ap Gwynn I, Nötzli HP (2003) Deformation of chondrocytes in articular cartilage under compressive load: a morphological study. Cells Tissues Organs 175: 133-139.

Kincaid SA, Evander SA (1985) En bloc staining of articular cartilage and bone. Stain Technol 60: 21-28

Kiviranta I, Tammi M, Jurvelin J, Säämänen A-M, Helminen HJ (1984) Fixation, decalcification and tissue processing effects of articular cartilage proteoglycans. Histochem 80: 569-573.

Lane LB, Bullough PG (1980) Age-related changes in the thickness of the calcified zone and the number of tidemarks in adult human articular cartilage. J Bone Joint Surg Br 62: 373-375.

Little K, Pimm H, Trueta J (1958) Osteoarthritis of the hip. An electron microscopic study. J Bone Joint Surg Br 40: 123-131.

MacConaill MA (1951) The movements of bones and joints. 4. The mechanical structure of articulating cartilage. J Bone Joint Surg 33: 251-257.

Mankin HJ (1962) Location of tritiated thymidine in articular cartilage of rabbits. I. Growth in immature cartilage. J Bone Joint Surg 44: 682-688.

Mankin HJ (1964) Mitosis in articular cartilage of immature rabbits. A histologic, stathmokinetic (colchicinic) and autoradiographic study. Clin Orthop 34: 170-183

McCall JG (1962) Scanning electron microscopy of articular cartilage. J Bone Joint Surg Br 51: 566.

Meachim G, Stockwell RA (1979) The matrix. In: Freeman MAR, ed. Adult articular cartilage. Second edition. Pitman Medical. 1-67.

Mendler M, Eich-Bender SG, Vaughan L, Winterhalter KH (1989) Cartilage contains mixed fibrils of collagen types II, IX and XI. J Cell Biol 108: 191-197.

Minns RJ, Stevens FS (1977) The collagen fibril organisation in human articular cartilage. J Anat 123: 437-457.

Módis L, Botos A, Kiviranta I, Lukácskó L, Helminen HJ (1996) Differences in submicroscopic structure of the extracellular matrix of canine femoral and tibial condylar articular cartilages as revealed by polarisation microscopical analysis. Acta Biologica Hungaria 47: 341-353.

Müller-Glauser W, Humbel B, Glatt M, Sträuli P, Winterhalter KH, Bruckner P (1986) On the role of type IX collagen in the extracellular matrix of cartilage: types IX collagen is localised to the intersections of collagen fibrils. J Cell Biol 102: 1931-1939.

O'Connor P, Orford CR, Gardner DL (1988) Differential response to compressive loads of zones of canine hyaline artilcuar cartilage: micromechanical light and electron microscopic studies. Annals Rheum Dis 47: 414-420.

Olivier P, Loeuille D, Watrin A, Walter F, Etienne S, Nelter P, Gillet P, Blum A (2001) Structural evaluation of articular cartilage. Potential contribution of magnetic resonance techniques used in clinical practise. Arth Rheum 44: 2285-2295.

Olsen BR, Ninomiya Y (1999a) Fibrillar collagens. In: Kreis T, Vale R, eds. Guidebook to the extracellular matrix, anchor and adhesion proteins. $2^{\text {nd }}$ Edition. Oxford University Press, Oxford. 383-387.

Olsen BR, Ninomiya Y (1999b) FACIT collagens. In: Kreis T, Vale R, eds. Guidebook to the extracellular matrix, anchor and adhesion proteins. $2^{\text {nd }}$ Edition. Oxford University Press, Oxford. 387-392.

Olsen BR, Ninomiya Y (1999c) Short chain collagens. In: Kreis T, Vale R, eds. Guidebook to the extracellular matrix, anchor and adhesion proteins. $2^{\text {nd }}$ Edition. Oxford University Press, Oxford. 392-395.

Orford CR, Gardner DL (1984). Proteoglycan association with collagen d band in hyaline articular cartilage. Connect Tissue Res 12: 345-348.

Otterness IG, Chang M, Burkhadt JE, Sweeney FJ, Milici AJ (1999). Histology and tidemark separation in hamsters. Vet Pathol 36: 138-145.

Poole AC, Ayad S, Gilbert RT (1992) Chondrons from articular cartilage. V. Immunohistochemical evaluation of type VI collagen organisation in isolated chondrons by light, confocal and electron microscopy. J Cell Sci 103: 1101-1110.

Redler I (1974) A scanning electron microscopic study of human normal and osteoarthritic cartilage. Clin Orthop 103: 262-268.

Shepard N, Mitchell N (1976) The localisation of proteoglycan by light and electron microscopy using Safranin O. A study of epiphyseal cartilage. J Ultrastruct Res 54: 451-460.

Silberberg R, Hasler M, Silberberg M (1966) Articular cartilage of dwarf mice: light and electron microscopic studies. Acta Anat 65: 275-298.

Silberberg R, Silberberg M, Feir D (1964) Life cycle of articular cartilage cells: an electron microscope of the hip joint of the mouse. Am J Anat 114: 17-47.

Silberberg R, Silberberg M, Vogel A, Wettstein W (1961) Ultrastructure of cartilage of mice of various ages. Am J Anat 109: 251-275.

Stockwell RA (1971) The interrelationship of cell density and cartilage thickness in mammalian articular cartilage. J Anat 109: 411-421.

Stockwell RA, Scott JE (1967) Distributions of acid glycosaminoglycans in human articular cartilage. Nature 215: 1376-1378.

Studer D, Michel M, Wohlwend M, Hunziker EB, Bushmann MD (1995) Vitrification of articular cartilage by high pressure freezing. J Microsc 179: 321-332.

Sweat F, Puchtler H, Augusta STR (1964) Sirius red F3BA as a stain for connective tissue. Arch Pathol 78: 6972.

Tepic S, Ito K (1997) Orientation mechanisms of collagen. In: Schneider E, ed. Biomechanik des meschlichen Bewegungsapparates. Springer-Verlag, Berlin 204-214.

Teshima R, Otsuke T, Takasu N, Yamagata N, Yamamoto (1995) Structure of the most superficial layer of articular cartilage. J Bone Joint Surg Br 77: 469-474.

Thomas JT, Ayad S, Grant ME (1994) Cartilage collagens: strategies for the study of their organisation and expression in the extracellular matrix. Ann Rheum Dis 53: 488-496.

Urban J (1994) The chondrocyte: a cell under pressure. Br J Rheum 33: 901-908. 
Urban JP, Maroudas A, Bayliss MT, Dillon J (1979) Swelling pressures of proteoglycans at the concentrations found in cartilaginous tissues. Biorheology 16: 447-464.

Vaughan L, Mendler M, Huber S, Bruckner P, Winterhalter KH, Irwin MI, Mayne R (1988) D-periodic distribution of collagen type IX along cartilage fibrils. J Cell Biol 106(3): 991-997.

Webber IT, Harrison RW, Iozzo RV (1996) Model structure of decorin and implications for collagen fibrillogenesis. J Biol Chem 271: 31767-31770.

Weiss C, Rosenberg L, Helfet AJ (1968) An ultrastructural study of normal young adult human articular cartilage. J Bone Joint Surg Am 50: 663-674.
Wotton SF, Duance VC (1994) Type III collagen in normal human articular cartilage. Histochem J 26: 412-416.

Wu JJ, Woods PE, Eyre DR (1992) Identification of cross-linking sites in bovine articular type IX collagen reveals an antiparallel type II-type IX molecular relationship and type IX to type IX bonding. J Biol Chem 267: 23007-23014.

Young MF, Xu T (2001) Creating transgenic mice to study skeletal function. In: Cowin SC, ed. Bone Mechanics Handbook (2nd Edition). CRC Press, London. 4.1 - 4.19.

Zarek JM, Edwards J (1963) The stress-structure relationship in articular cartilage. Med Elec Biol Engin 1: 497-507. 